\title{
Michale J. Graetz: The End of Energy
}

\author{
The MIT Press, Cambridge, MA, USA
}

\author{
J. T. Trevors
}

Published online: 29 June 2011

(C) Springer Science+Business Media, LLC 2011

The End of Energy is an outstanding book by the scholar, Professor Michael J. Graetz, on the complicated topic of energy policies and the multitude of intertwined connections (and mistakes made) to economics, global markets, politics, regulations, legislation, conservation, climate change and disasters. Each chapter is presented from an historical perspective that weaves the facts into a connected complete story. The actual story is still in progress day-today as vast amounts of oil are imported into many countries, not just the United States. This masterfully crafted book explains the loss of control by the United States over the once cheap oil from Middle Eastern countries. Professor Graetz then examines the emergence of environmental organizations that challenged the nuclear energy and environmental pollution.

Professor Graetz dissects and reconstructs four decades of energy policy and the mistakes made, deliberate or otherwise, in the United States. Mistakes have consequences, locally, nationally and internationally. Attempts to redirect energy policies to significant less dependency on fossil fuels have failed. The outcome is the present situation where we have the increasing use of fossil fuels and global climate change being accelerated by too many humans producing too much waste. Without oil, countries and economies simply do not function. Central to energy policies is the price of oil, the number one globally traded item. Even today, the full cost of oil extraction, shipping, refining, public health effects and pollution caused is not reflected in the price of oil.

This book is a must read for all people interested in energy policies and our biosphere. This book should be read, studied and comprehended by as many people as possible. To ignore the knowledge in this book is a grave mistake for humanity. There are no easy technological fixes to energy sources, energy consumption and the resulting global pollution. Moreover, the obstacles to correcting the present global situation are mostly political, profound and powerful.

Reviewed by J. T. Trevors.

J. T. Trevors $(\square)$

School of Environmental Sciences, University of Guelph,

Guelph, ON N1G 2W1, Canada

e-mail: jtrevors@uoguelph.ca 